\title{
The comparative of Loneliness and its related factors in rural and urban
}

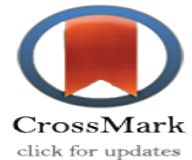

\section{elderly people in Behshahr city}

\section{Salehi Tilaki E ${ }^{1}$ * ${ }^{*}$ lali ES ${ }^{2}$, Taraghi Z ${ }^{3}$, Mousavinasab N}

1- MSc Student, Department of Nursing, Nasibeh Nursing and Midwifery Faculty, Mazandaran University of Medical Sciences, Sari, Iran.

2- Department of Geriatric Nursing, Nasibeh Faculty of Nursing and Midwifery, Mazandaran University of Medical Sciences, Sari, Iran (Corresponding Author)

E-mail: paradis2082000@yahoo.com

3- Department of Geriatric Nursing, Nasibeh Faculty of Nursing and Midwifery, Mazandaran University of Medical Sciences, Sari, Iran.

4- Department of Biostatistics and Epidemiology, Faculty of Health. Mazandaran University of Medical Sciences, Sari, Iran.

\section{Abstract}

Introduction: Little is known about characteristics of loneliness among rural and urban older people. The purpose of this study was to determine Loneliness comparison and its related factors between urban and rural elderly people.

Method: In this descriptive study, 280 community dowelling elderly people were selected by systematic random sampling method in Behshahr city in 2018. Data were gathered using Social and Emotional Loneliness Scale for Adults (SELSA) questionnaire, Instrumental Activities of Daily Living Index (IADL), and the Medical-Demographic questionnaire. Data were Analyzed by SPSS 22.0 software using descriptive statistics, via the independent t-test, one-way ANOVA test, Mann-Whitney test, Kruskal-Wallis test and Multiple Linear regression with stepwise analysis.

Results: The mean of Loneliness score for the urban and rural elderly were $33.00 \pm$ 8.34 and $33.57 \pm 9.89$, respectively. There was no significantly relationship between total loneliness score among urban and rural elderly, however emotional score was significantly more among rural elderly compared to urban elders $(\mathrm{P}=0.033)$. According to the multivariate linear regression analysis results, marital status had the most strongly affected on the sense of loneliness among both urban and rural elders.

Conclusion: Regarding the high incidence of loneliness in the elderly, Perforrming more studies and designing educational, consulting, and supportive interventions is suggested, in order to prevent of loneliness and its adverse outcomes.

Key words: Elderly, Loneliness, Urban, Rural, Related Factors.

Received: 11 May 2019

Accepted: 14 August 2019

\begin{tabular}{|l|l|}
\hline \multicolumn{3}{|c|}{ Access this article online } \\
\hline
\end{tabular}




\title{
مقايسه احساس تنهايى و عوامل مرتبط با آن در سالمندان شهرى و روستايى شهر ستان بهشر
}

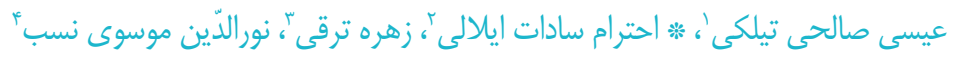

ا - كارشناسى ارشد، كروه يرستارى سالمندى، دانشكده يرستارى و ماميايى نسيبه سارى، مازنداران، ايران.

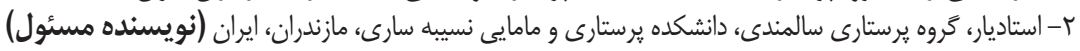
يست الكترونيكى: Paradist.1r...@Yahoo.com

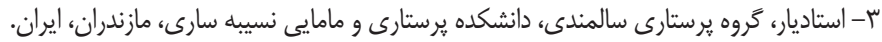

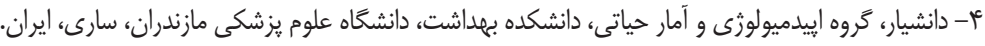

نشريه سالمندشناسى دوره سماره F Pبهار

مقدمه: اطاعات كمى در مورد ويزَى هاى احساس تنهايى سالمندان شهرى و روستايى وجود دارد. هدف از انجام اين يزوهش، تعيين مقايسه اى احساس تنهايى و عوامل مرتبط با آن در سالمندان شهرى و روستايى مراجعه كننده به مراكز بهداشتى شهرست ورتان بهشهر

روش: در اين مطالعه توصيفى-تحليلى، • ^r سالمند ساكن منزل شهرستان بهشهر با روش تصادفى سيستماتيك انتخاب شدند.

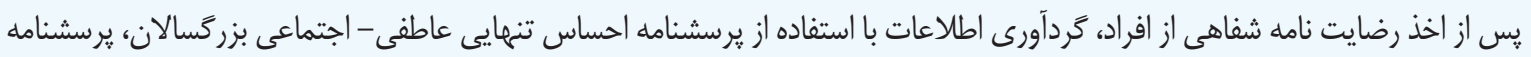
فعاليت هاى روزمره زندگى ابزارى و يرسشنامه جمعيت شناختى - طبى انجام شد. تجزيه و تحليل داده ها با استفاده از نرم افزار آمارى SPSS

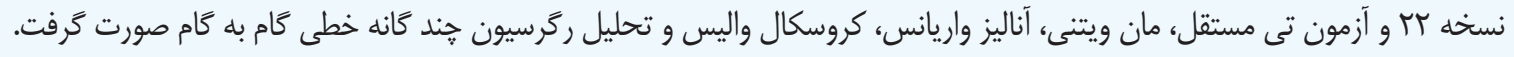

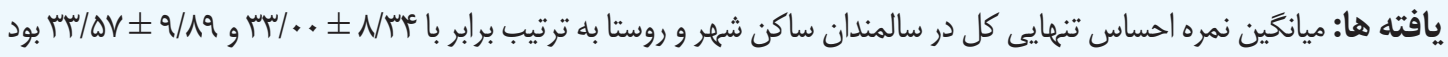
و اختلاف معنى دارى نداشت(ه) ••P>). ميانگين نمره زير حيطه عاطفى احساس تنهايى در سالمندان روستايى به طور معنى دارى بيش تر

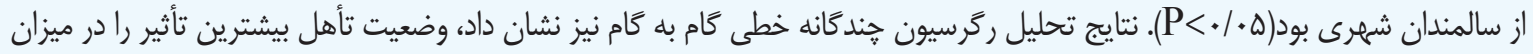
احساس تنهايى سالمندان شهرى و روستايى داشت. تتيجه كَيرى: با توجه به شيوع بالاى احساس تنهايى در سالمندان، انجام مطالعات بيش تر و طراحى مداخلات آموزشى - مشاوره اى - حمايتى جهت مقابله با احساس تنهايى سالمندان و يبشخَيرى از يى آمدهاى نامطلوب آن توصيه مى شود. كليدوازه ها: سالمندى، احساس تنهايى، شهرى، روستايى، عوامل مرتبط.

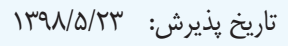

خود را از دست مى دهند (أ). يكى از مهمترين خالش هاى آسيب

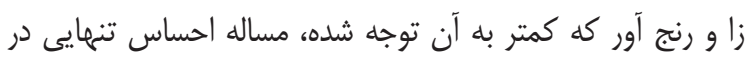

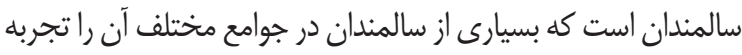

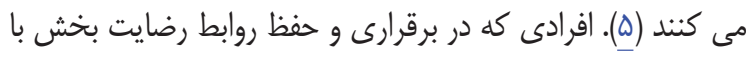

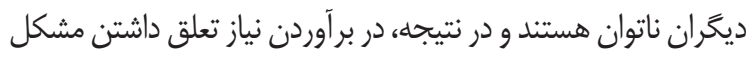

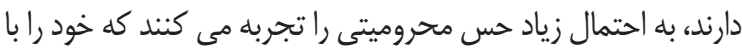

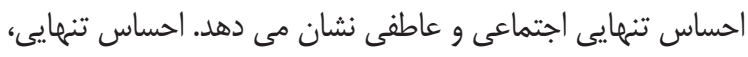
ترس از دست دادن و اضطراب، از علائم رايج ناكفايتى روابط بين

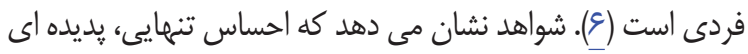

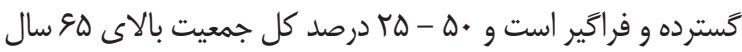
را بر حسب سن و جنس تحت تأثير قرار مى دهد (V).

\section{مقامه}

بر اساس تعريف سازمان بهداشت جهانى در كشورهاى توسعه

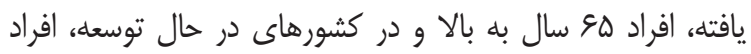

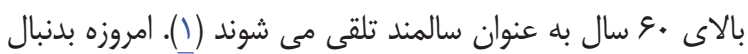

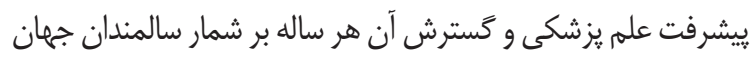

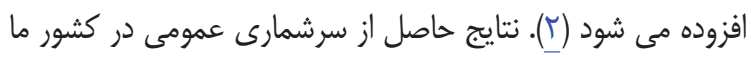

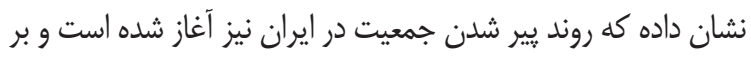

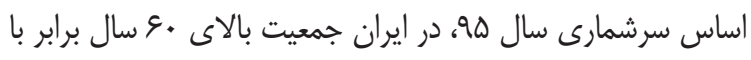

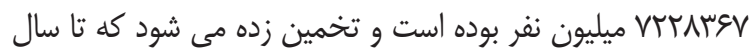

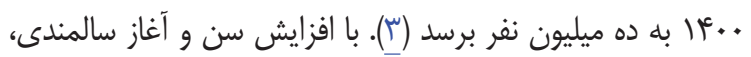

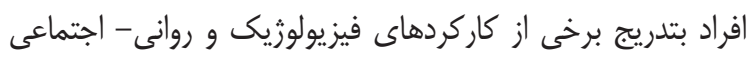


اطلاعات در مورد ويزَيَيهاى احساس تنهايى سالمندان شهرى و روستايى كشورمان و با در نظر داشتن اين كه با شناسايى و اولويت

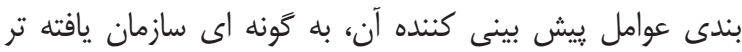

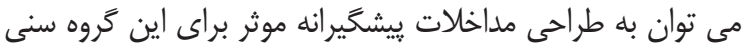

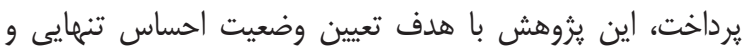
عوامل مرتبط با آن در سالمندان شهرى و روستايى انجام كرديد.

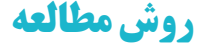

در اين مطالعه توصيفى - تحليلى، جامعه آمارى شامل كليه

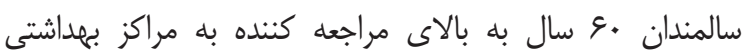

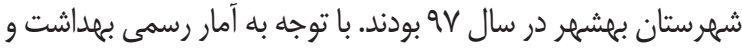
1.

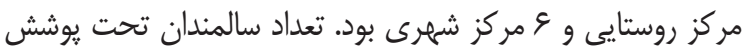

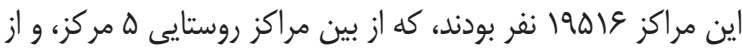

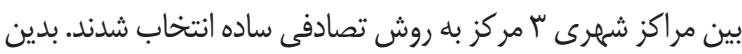

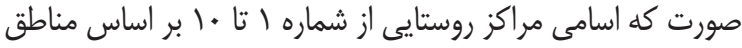

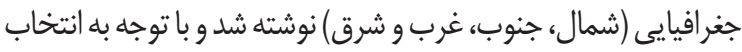

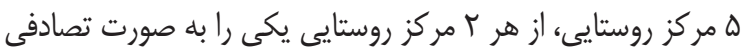

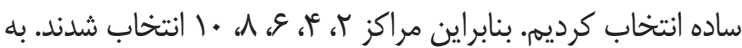

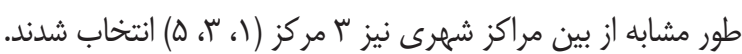
بر اساس فرمول برآورد ميانكَين احساس تنهايى (TV)، تعداد حجم

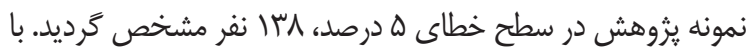

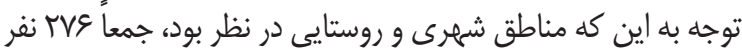

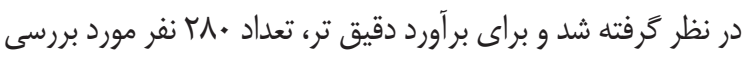

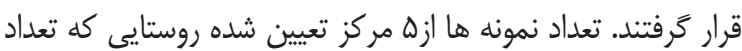

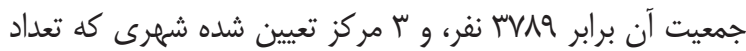
جمعيت آن ^م+.9 نفر بود، به نسبت تعداد جمعيت هر مركز و با با روش سهميه اى انتخاب شدند. نمونه كيرى در هر مركز از بين كليه افراد

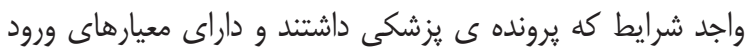

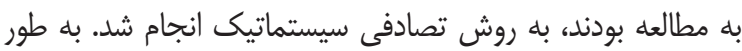

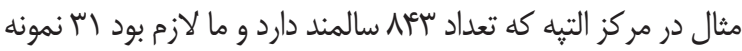

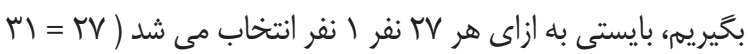

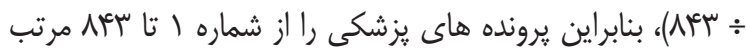

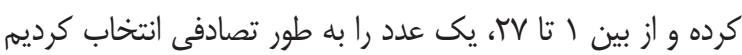
كه در اينجا عدد ها انتخاب شده بود، بنابراين يرونده هاى شماره

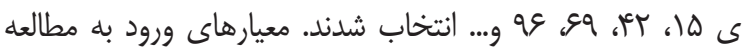
شامل: سالمندان •ع سال و بالاتر، داشتن نمره شناخت عأو و بالاتر

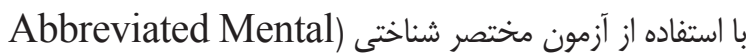

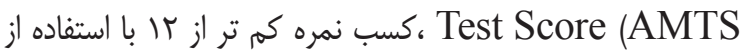
مقياس افسردگى سالمندان Geriatric Depression Scale
احساس تنهايى داراى دو بعد اجتماعى و عاطفى است. بعد اجتماعى را انزواى اجتماعى ذهنى نيز ناميده اند كه با انزواى

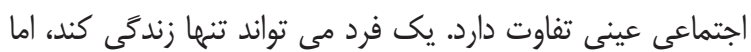

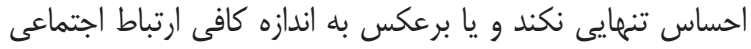

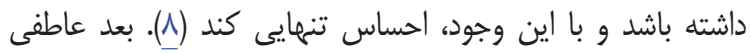
احساس تنهايى ناشى از شكاف ميان روابط بين فردى موجود از نظر

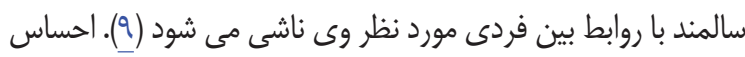

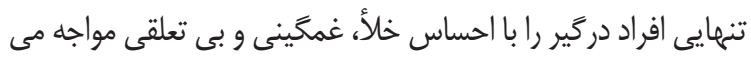
كند و به شيوه هاى مختلف بر تعاملات اجتماعى با ديخران، نحوه

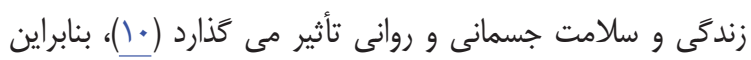
شناسايى عواملى كه ييش بينى كننده و مرتبط با احساس تنهايى در

سالمندان هستند، از اهميت ويزه اي برخوردار است (II) عوامل متعددى بر روى احساس تنهايى تاثير مى كذارند مانند سن، جنس، وضعيت تاهل، سطح تحصيلات، وضعيت درآمد،

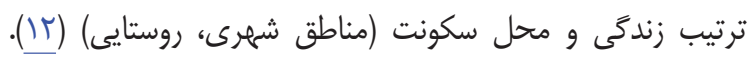
احساس تنهايى ارتباطى قوى با سطح تحصيلات بإيين، بيوه بودن،

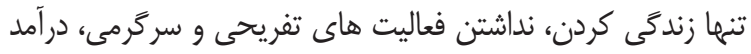

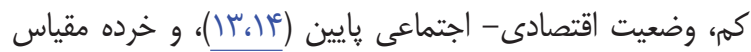

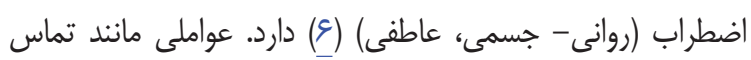

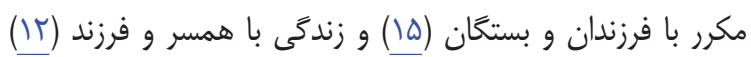
مى تواند احساس تنهايى را كاهش دهد. در واقع، روابط خانوادگى دئ

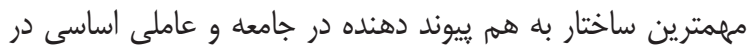
كاهش احساس تنهايى سالمندان مى باشد (19)، سالمندانى كه حمايت بيشترى از شبكه هاى اجتماعى دريافت مى كنتلد، كمتر

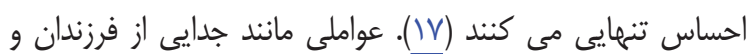

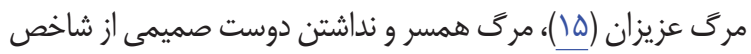

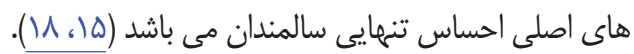
مطالعات بسيارى اثرات مضر احساس تنهايى رالئ را نشان داده

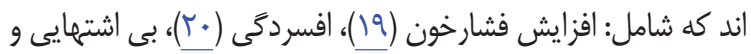

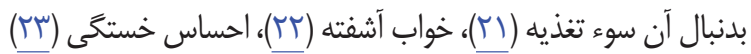
وسوء مصرف الكل (بأ) مى باشد. اطلاعات كمى در مورد ويزَيهاى احساس تنهايى سالمندان

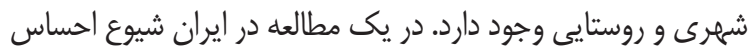

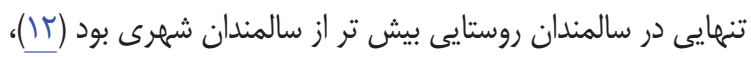
درمطالعه اي در جين نيز، احساس تنهايى سالمندان روستايى بيش تر از سالمندان شهرى بود (ها). در بررسى ديخرى در كانادا، ييش بينى

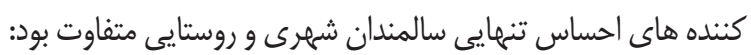
با عنوان مثال مهمترين عامل احساس تنهايى سالمندان روستايى،

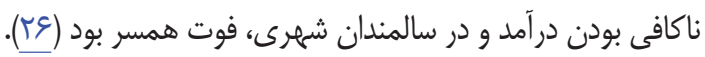
با توجه به تناقضات يافته هاى مطالعات انجام شده وكمبود 
قرار داده مى شود. اخذ امتياز ع-• نشانگ死 عدم وجود افسردگى،

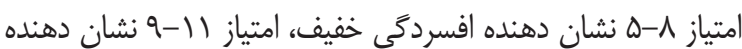

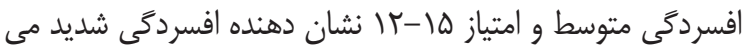

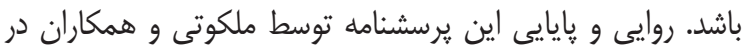

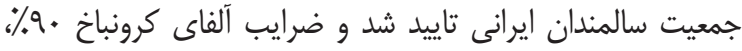

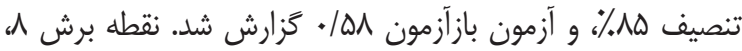

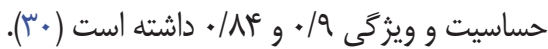

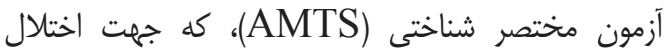

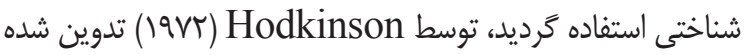
است. اين آزمون يك يرسشنامه • ا سوالى دو گزينه ايى است و داراى اعتبار و سرعت بالاى ارزيابى شناختى در بيماران سالخورده است.

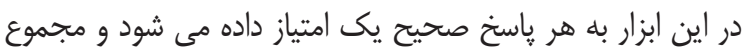

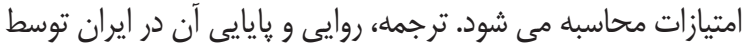

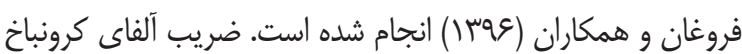

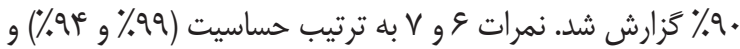

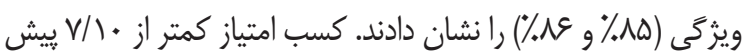
بينى كننده اختلال شناختى محسوب مى شود (آس).

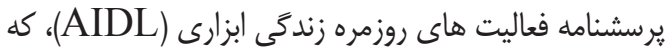

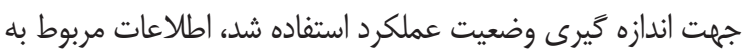

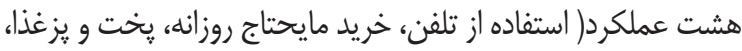
نخمهدارى و نظافت منزل، شست و شوى لباس ها، استفاده از وسايل

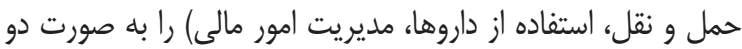

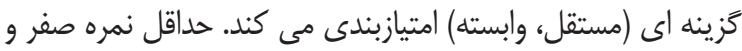

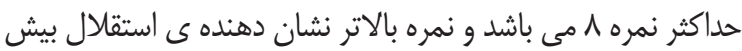

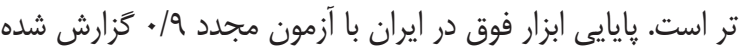

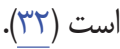

يرسشنامه عوامل مرتبط جمعيت شناختى - طبى شامل: سن، جنس، وضعيت تاهل، محل سكونت، سطح تحصيلات، همراهان

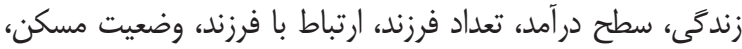

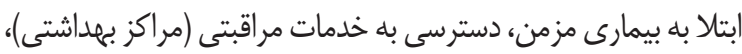
نقايص شنوايى، نقايص بينايى و سابقه سقوط بود كه توسط يثروهشَّر

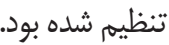
روش اجرا و ملاحظات اخلاقى لودى يزوهشگً در طول روزهاى هفته به مراكز مربوطه مراجعه مانه

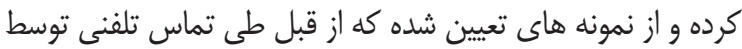

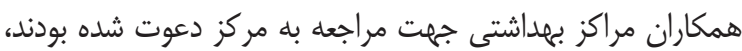

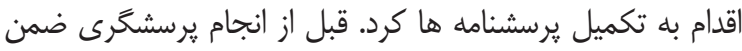

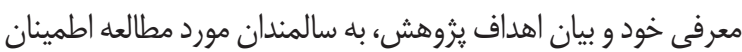

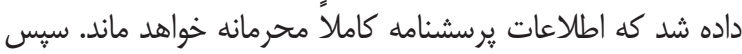
رضايت آنها بصورت شفاهى اخذ و به آنها اطلاع داده شد كه شركت
(GDS

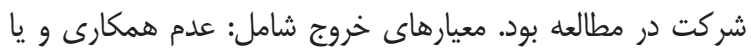
عدم رضايت براى تكميل فرايند مطالعه بود.

$$
n=\left(\frac{Z_{1-\alpha / 2} \sigma}{d}\right)^{2}
$$

$$
\mathrm{n}=(1 / 9 \varepsilon \times 1) / 4)^{2}=14 \mathrm{~s}
$$

ابزاركردآورى اطلاعات در اين يزوهش شامل: يرسشنامه

احساس تنهايى عاطفى - اجتماعى بزرگسالان Social and Emotional Loneliness Scale for Adults- Short form) SELSA مختصر شناختى (AMTS)، يرسشنامه فعاليت هاى روزمره زندگى ابزارى (nstrumental Activities of Daily Living) AIDL مقياس احساس تنهايى عاطفى و اجتماعى بزرگسالان Best Ditommaso - Brannen Sوسط (SELSA_S)

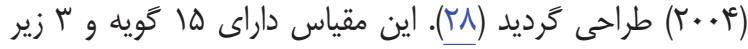
مقياس؛ احساس تنهايى رمانتيك (ينج گَويه)، خانوادگى (ينج گَّيه)

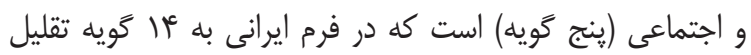
يافته است. اين يرسشنامه بر روى طيف ليكرت ه كَزينه اى از كاملا

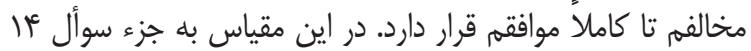
تمامى سوالات ديخر به صورت معكوس نمره گذارى مى شوند

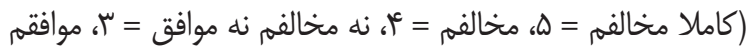

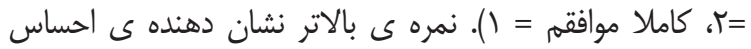
تنهايى عاطفى - اجتماعى بيش تر مى باشد. احساس تنهايى عاطفى،

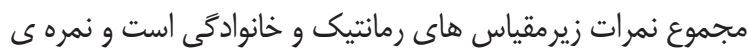
احساس تنهايى اجتماعى نيز با نمرهى زير مقياس تنهايى اجتماعى

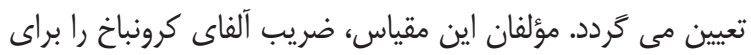

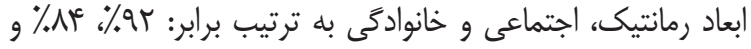

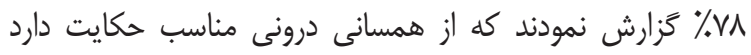

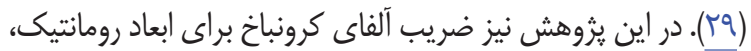

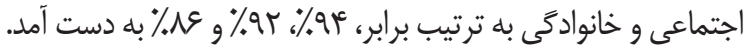

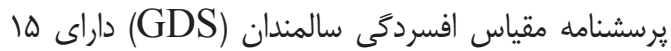

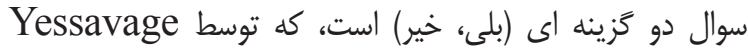

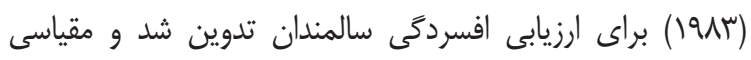

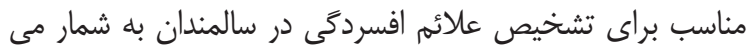

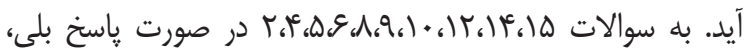
يك نمره اختصاص داده مى شود و به آيتم خير نمره داده نمى شود.

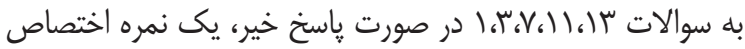

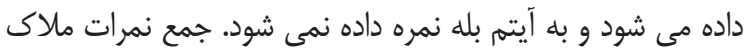




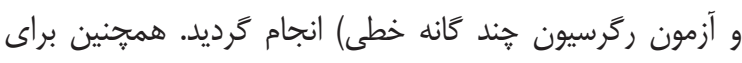

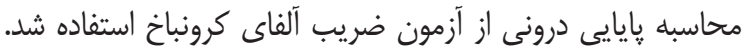

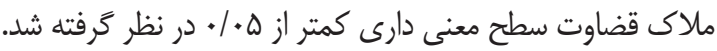

\section{بافته هنا}

از ميان •r سالمندى كه وارد مطالعه شدند •.rا نفر

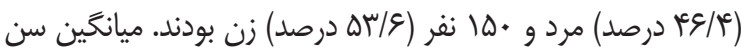

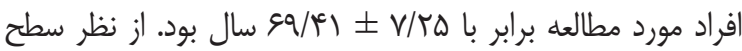

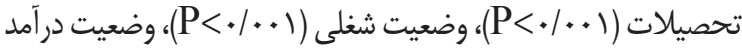

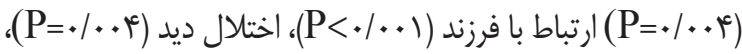

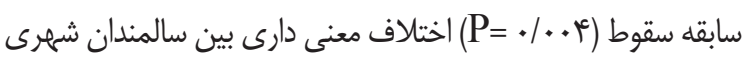

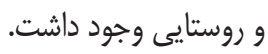
بين ميانكين نمره كل احساس تنهايى سالمندان شهرى

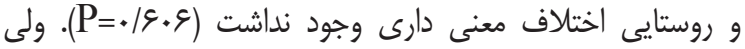

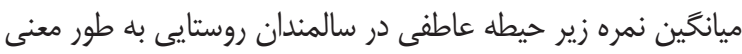

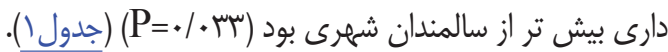

در مطالعه كاملاً اختيارى است. همجنين با توجه به اينكه ممكن

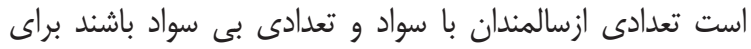

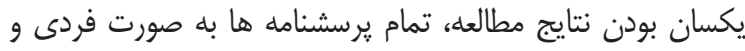
با مصاحبه ى جهره به جهره توسط محقق تكميل شد. ضمناً اكر سالمندى به دليل خاصى (معلوليت و عدم تحرك) قادر به مراجعه

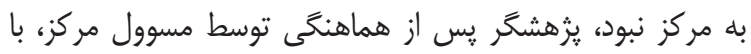

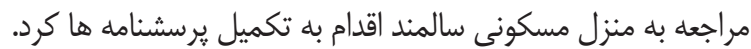

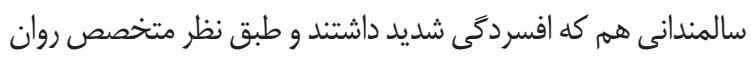
يزشكى دارو مصرف مى كردند، از مطالعه حذف شدند و آنهايى كه

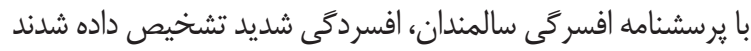

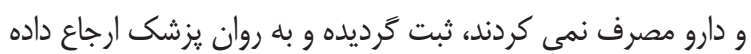
شدند. زمان مورد نياز جهت تكميل برسشنامه ها براى هر سالمنده،

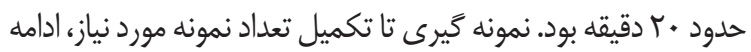
يافت و در حدود سه ماه به طول انجاميد.

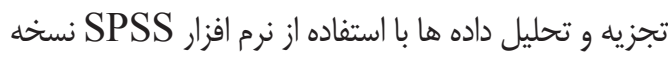

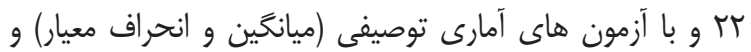

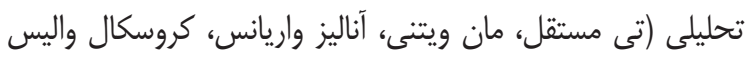

جدول (: مقايسه ميانكين نمره كل احساس تنهايى و زير مقياس هاى آن در سالمندان مراجعه كننده به مراكز بهداشتى شهرستان بهشهر به تفكيك محل سكونت (VIr)

\begin{tabular}{|c|c|c|c|}
\hline \multirow[b]{2}{*}{$\mathrm{P}$-value } & \multicolumn{2}{|c|}{ محل سكونت } & \multirow[b]{2}{*}{ احساس تنهايى } \\
\hline & انحراف معيارد ميانخين & انحراف معيار土 ميانخين & \\
\hline .19 .9 & $\Pi / / \Delta V \pm q / \wedge q$ & ع & تنهايي \\
\hline سبر./.* & $r .1 .9 \pm g / F r$ & $\mid N / F \cdot \pm \Delta / 1 \Delta$ & \\
\hline.$/ 9 V T$ & $1 r / l r \pm r / q 9$ & $\mid r / f \Lambda \pm r / \varepsilon q$ & $\checkmark$ \\
\hline
\end{tabular}

$* \mathrm{P}<\cdot / \cdot \Delta$

بيشترى نسبت به سالمندان مرد داشتند. در سالمندان روستايى، گرجه ميانخين نمره كل احساس تنهايى و مقياس عاطفى و اجتماعى سنى

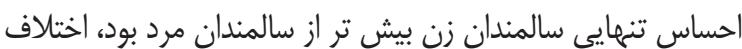

معنى دار نداشت (جدول r).

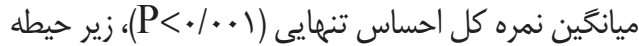

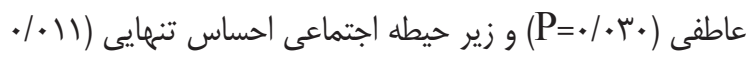
(P=

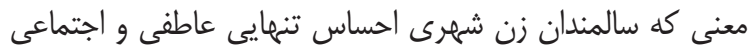
جدول ب: مقايسه ميانكَين نمره كل احساس تنهايى و زير مقياس هاى آن در سالمندان شهرى و روستايى مراجعه كننده به مراكز بهداشتى شهرستان بهشهر به تفكيى

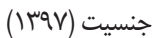

\begin{tabular}{|c|c|c|c|c|c|}
\hline \multicolumn{4}{|c|}{ محل سكونت } & \multirow[b]{3}{*}{ جنسيت } & \multirow[b]{3}{*}{ احساس تنهايى } \\
\hline \multicolumn{2}{|c|}{ روستا } & \multicolumn{2}{|r|}{ شهر } & & \\
\hline $\mathrm{P}$ & انحراف معيار土 ميانخين & $\mathrm{P}$ & انحراف معيار土 ميانحين & & \\
\hline . & $\begin{array}{l}r Y / \Lambda T \pm \Lambda / \Lambda \Delta \\
r Y / \cdot \Lambda \pm 1 \cdot / \Delta V\end{array}$ & $* .1 \ldots$ & $r \cdot / \uparrow \wedge \pm \varepsilon / \Lambda$ & 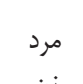 & تنهايى كل \\
\hline ./4at & $\begin{array}{l}|N / Q \Lambda \pm \Delta / \mu| \\
r \cdot|\Lambda| \pm V / \cdot r\end{array}$ & $* . / \cdot r$. & $\begin{array}{l}I V / r r \pm r / T V \\
I V / \Delta \Lambda \pm \Delta / V V\end{array}$ & مرد & طفى \\
\hline - MTE & $\begin{array}{l}\mid r / \Delta \Lambda \pm r / q \gamma \\
|r / \Lambda| \pm \Delta / . .\end{array}$ & $* .1 .11$ & $\begin{array}{l}\mid r / \Delta \xi \pm r / \kappa . \\
\mid \phi / \kappa \wedge \pm r / \kappa q\end{array}$ & مرد & اجتماعى \\
\hline
\end{tabular}

$* \mathrm{P}<\cdot / \cdot \Delta$ 
در سالمندان شهرى و روستايى داشت. به عبارت ديخر سالمندان با تحصيلات بالا، متأهل بودن، زندگى با همسر و فرزندن، ارتباط بيشتر

با فرزندان، كمتر احساس تنهايى مى كردند (جدولِّ).
با مقايسه ميانكَين نمره كل احساس تنهايى ميان متغيرهاى

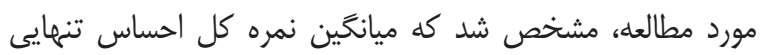

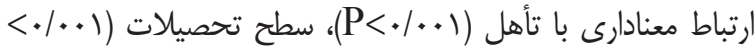
P

جدول "ا: مقايسه ميانكَين و انحر اف معيار نمره كل احساس تنهايى با متغيرهاى جمعيت شناختى سالمندان مراجعه كننده به مراكز بهداشتى شهرستان بهشهر سال (Vوس ()

\begin{tabular}{|c|c|c|c|c|c|}
\hline \multicolumn{4}{|c|}{ احساس تنهايى كل } & \multirow{3}{*}{\multicolumn{2}{|c|}{ متعير متر }} \\
\hline \multicolumn{2}{|r|}{ روستا } & \multicolumn{2}{|r|}{ شهر } & & \\
\hline $\mathrm{p}$ & انحراف معيار土 ميانخين & $\mathrm{p}$ & انحراف معيار土 ميانگين & & \\
\hline$* / \ldots$ & $\begin{array}{l}r y / q r \pm q / r V \\
r / r r \pm q / q \Psi\end{array}$ & $* / \ldots$ & $\begin{array}{l}r \cdot / \cdot q \pm q / \Lambda r \\
r q / r r \pm V / A V\end{array}$ & همسر فوت شده و مطلقه & وضعيت تأهل \\
\hline${ }^{*} \cdot / . .1$ & $\begin{array}{l}r r / q \Psi \pm q / q \varepsilon \\
r N / 11 \pm q / r . \\
r \cdot / \cdot \Delta \pm \Lambda / \uparrow \Lambda \\
r q / q q \pm 1 \cdot / q r\end{array}$ & $* / \ldots$ & 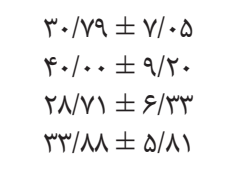 & 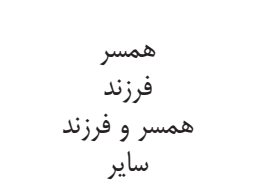 & همراه زندگى \\
\hline${ }^{*} \cdot / \cdot r$. & $\begin{array}{l}r \Delta / \cdots \pm q / V \cdot \\
r r / \Lambda I \pm 1 \cdot / q \Delta \\
r q / / V \pm r / \Delta r \\
r V / V \Delta \pm N / r r \\
r / / \cdots \pm 1 / r q\end{array}$ & $*$ & $\begin{array}{l}r V / \wedge q \pm q / \Delta . \\
r F / \cdot V \pm V / r \Delta \\
r \cdot / \wedge r \pm \Delta / v) \\
r q / v \cdot \pm q / q q \\
r \Delta / \cdot . \pm \Delta / \kappa r\end{array}$ & رابتد سواد & سطح تحصيلات \\
\hline.$/ 4 t$. & $\begin{array}{l}r / / l \pm q / \| V \\
r w / q \Delta \pm q / q \Delta \\
r / \Delta V \pm q / \Delta q\end{array}$ & $* / \ldots$ & $\begin{array}{l}r N / V r \pm g / q \Lambda \\
r \cdot / \Delta r \pm V / V r \\
r q / \Lambda r \pm V / q 1\end{array}$ & بازنشسته & وضعيت شغل فعلى \\
\hline.$/ 194$ & $\begin{array}{l}r \omega / r \cdot 1 \cdot \pm / q) \\
r r / \cdots \pm q / r \cdot \\
r r / . . \pm \\
r q / \varphi \phi\end{array}$ & $*$ & 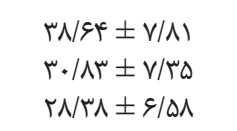 & بيشتر برابر هزئ هزينه كرد كرد & وضعيت درآمد \\
\hline . & $\begin{array}{l}r r / \varphi) \pm q / v \Lambda \\
r \psi / \Delta \cdot \pm q / r q\end{array}$ & $* .1 .99$ & $\begin{array}{l}r r / q q \pm N / 1 \omega \\
\kappa V / . . \pm F / r \omega\end{array}$ & ملكى اجى & وضعيت مسكن \\
\hline${ }^{*} \cdot / \cdot \cdot v$ & $\begin{array}{l}r r / \& q \pm q / \Lambda . \\
r r / V \Psi \pm q / T V \\
r / / F \cdot \pm \Lambda / V T \\
r \cdot / \varepsilon \cdot \pm 1 \cdot / \& \phi\end{array}$ & $*$ & 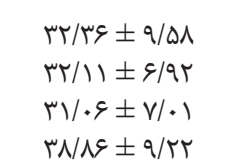 & 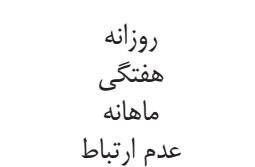 & ارتباط با فرزند \\
\hline
\end{tabular}

$* \mathrm{P}<\cdot / \cdot 0$

جدول f : تحليل رَّرسيون جندكانه خطى بين نمره كل احساس تنهايى و متغيرهاى جمعيت شناختى در سالمندان شهرى

\begin{tabular}{|c|c|c|c|c|c|}
\hline P-value & ضريب آمارى & ضريب استاندارد & $\begin{array}{c}\text { خطاى استاندارد } \\
\text { SE }\end{array}$ & $\begin{array}{c}\text { ضريب غياردارد } \\
\text { b }\end{array}$ & متغير \\
\hline 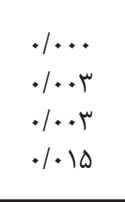 & $\begin{array}{c}r / V \Lambda \\
-r / q \Lambda \\
r / . . \\
r / \& q\end{array}$ & 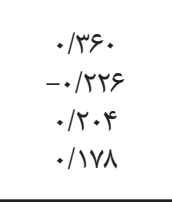 & $\begin{array}{l}1 / \mu F \\
. / 41 \\
r / M 1 \\
. / 9 V\end{array}$ & $\begin{array}{l}G / F F \\
-1 / T r \\
11 / \& \Lambda \\
T / F .\end{array}$ & فواليت روزمره زندأهلى \\
\hline
\end{tabular}

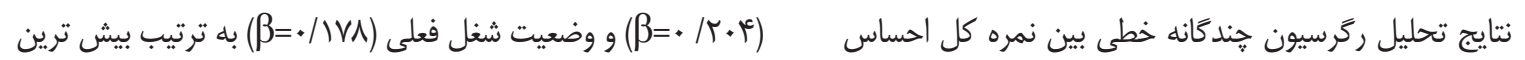

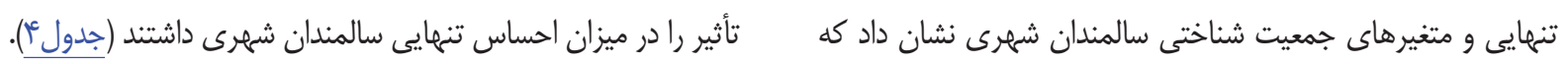

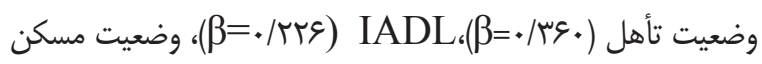


تحصيلات(ه+r/•-- = $\beta)$ به ترتيب بيش ترين تأثير را در ميزان احساس تنهايى سالمندان روستايى داشتند (جدوله).
نتايج تحليل ركر سيون جندكانه خطى بين نمره كل احساس تنهايى و متغيرهاى جمعيت شناختى در سالمندان روستايى نشان داد

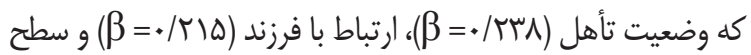

جدول ه : تحليل ركر سيون جندكانه خطى بين نمره كل احساس تنهايى و متغيرهاى جمعيت شناختى در سالمندان روستايى

\begin{tabular}{|c|c|c|c|c|c|}
\hline P-value & ضريب آمارى & ضريب استاندارد & $\begin{array}{c}\text { خطاى استاندارد } \\
\text { SE }\end{array}$ & ضريب غير استاندارد & متغير \\
\hline r... & $r / 91$ & גזr/. & $1 / v 9$ & $\Delta / \mu V$ & وضعيت تأهل \\
\hline.$/ \cdot V$ & $r / V^{e}$ & . / TIO &.$/ 99$ & $r / N$ & ارتباط با فرزندان \\
\hline .1 .11 & $-r / \Delta$. & $-\cdot / r \cdot \Delta$ & . / $\Delta$ & $-r / 19$ & سطح تحصيلات \\
\hline
\end{tabular}

Phaswana-Mafuya نتايج مطالعه Haney و همكاران (YV)، Hazer و همكاران (1) (1)،

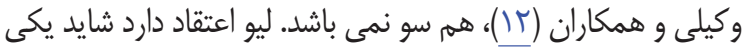
از دلايل بالا بودن احساس تنهايى در زنان اين است كه آنها جون آنون

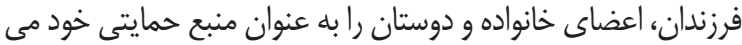
دانند، به دنبال سالمندى و تغييرات در ابعاد روان شناختى، بعد روحى في إنى

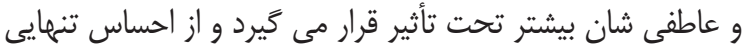
شاكى هستند (•) نتايج مطالعه حاضر نشان داد، هم در سالمندانى شهرى و هم روستايى وضعيت تأهل بيش ترين عامل ييش بينى كننده احساس

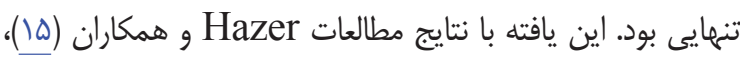

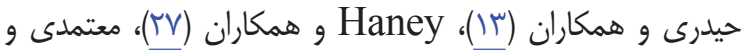

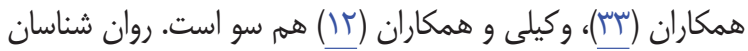
معتقدند نقش هاو الكوهاى يذيرفته شده اجتماعى در درك احساس

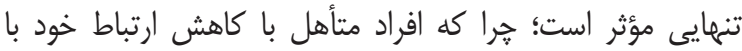

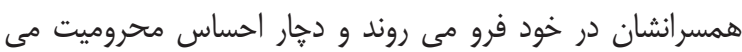
شوند. محدوديت يا ناتوانى در ايفاى اين نقش ها، ميزان احساس

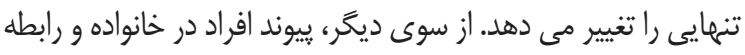
عاطفى با همسران مى تواند ارتباط اجتماعى مؤثر را فراهم كند و داني

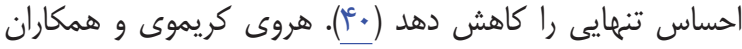
در يثوهش كيفى خود به اين نتيجه رسيدندكه سالمندانى كه همسر الهر

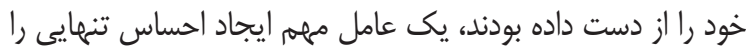

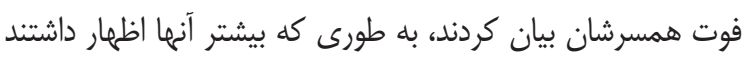
كه ازدواج مجدد مى تواند در كاهش احساس تنهايى و حس تعلق

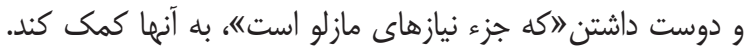

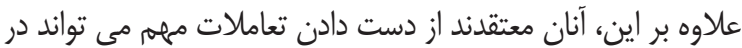
يقى فوت، طلاق، رهاشدگى يا فقدان حمايت هاى عاطفى و خانوادَّى ايجاد شود (الأ). نتايج به دست آمده نشان داد بين نمره كل احساس تنهايى و

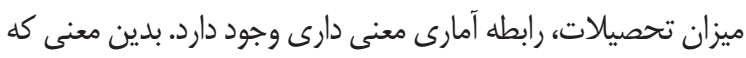

در مطالعه حاضر، مشخص شد ميانگين نمره كل احساس تنهايى سالمندان شهرى و روستايى اختلاف معنى دار نداشت. اين يافته با نتايج مطالعه معتمدى و همكاران تحت عنوان بررسى ميزان احساس تنهايى عاطفى و اجتماعى در سالمندان ساكن شهرستان اصفهان (سب) و مطالعه AKIRA - NARUSAWA و همكاران تحت عنوان بررسى احساس تنهايى و عوامل مرتبط با آن در

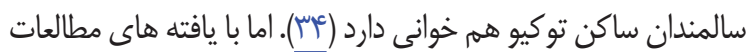

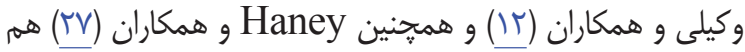
سو نمى باشد. در مطالعه آنها سالمندان ساكن روستا، احساس تنهايى بيشترى نسبت به سالمندان شهرى داشتند. سالمندانى كه در روستا

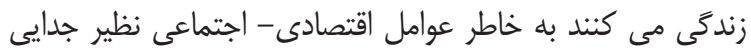
جغرافيايى و اجتماعى از جامعه بزرى تر شهرى، محدوديت دسترسى بهى

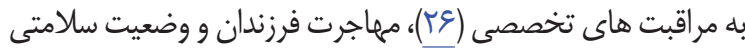

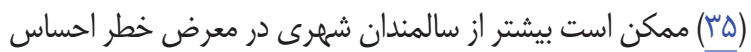

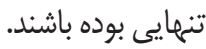

همجنين در مطالعه حاضر مشخص شد، نمره زير حيطه عاطفى احساس تنهايى در سالمندان روستايى به طور معنى دارى داضي بيش تر از سالمندان شهرى بود. در تبيين يافته فوق مى توان كَفت؛

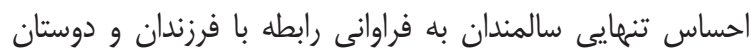
مربوط نمى شود بلكه بيشتر به انتظارات و رضايت از اين ارتباط ها

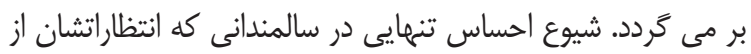

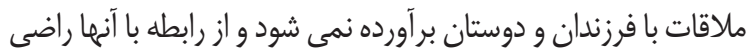

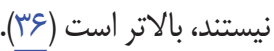
يافته هاى مطالعه حاضر نشان داد كه اثر جنسيت بر ميانخين نمره كل احساس تنهايى و زير مقياس عاطفى و اجتماعى آن، فقط در سالمندان شهرى معنى دار بود. به اين صورت كه سالمندان زن إن، احساس تنهايى عاطفى و اجتماعى بيشترى نسبت به سالمندان

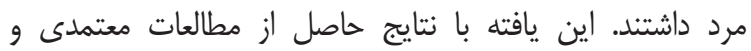

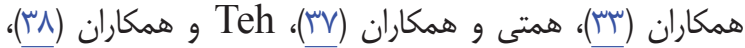


با توجه به شيوع احساس تنهايى در سالمندان، يِيشنهاد مى

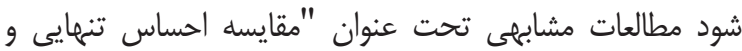
عوامل مرتبط با آن بين سالمندان ساكن جامعه با سالمندان ساكن آسايشگاه هاى سالمندى و غيره" انجام گيرد. محدوديت ها

از جمله محدوديت هاى اين مطالعه، كم حوصله بودن برخى سالمندان به هنگًام ياسخ به سؤالات يرسشنامه بود. بدين خاطر

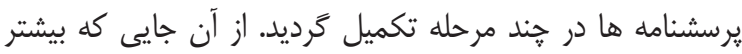

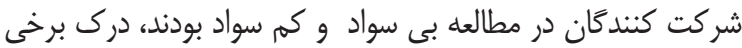

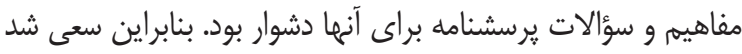

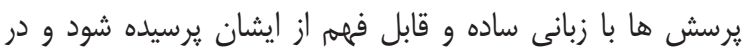

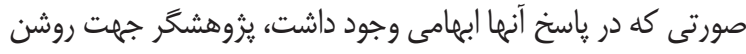
شدن مطلب، توضيحات بيش ترى درخواست مى كرد (كه به دليل اتلاف وقت يكى از محدوديت هاى يثوهش محسوب مى شى شد). و

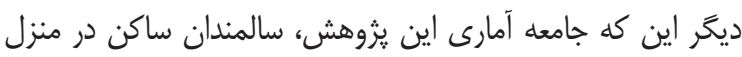

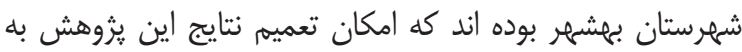
سالمندانى كه در خانه سالمندان زندگى مى كنند، وجود ندارد.

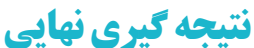

سالمندانى كه متأهل بودند، تحصيلات بالاتر داشتند، با همسر و فرزند زندگى مى كردند و ارتباط بيشترى با فرزندان داشتند، احساس تنهايى كمترى مى كردند. همجنين در سالمندان شهرى

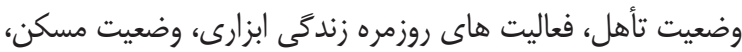
وضعيت شغل فعلى و در سالمندان روستايى وضعيت تأهل، ارتباط با فرزند و سطح تحصيلات به ترتيب نقش معنادارى در ييش بينى

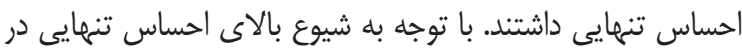

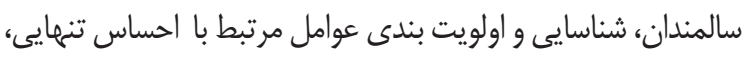
از اهميت بالايى برخوردار است و مى تواند به طراحى مداخلات

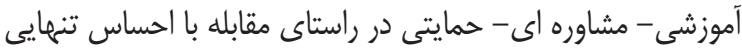
و در نهايت افزايش سلامت سالمندان و ييشخَيرى از يى آمدهاى نامطلوب آن مورد استفاده قرار بخيرد.

\section{تشكر و قدر هانى}

اين يزوهش بر گرفته از پايان نامه ى كارشناسى ارشد به

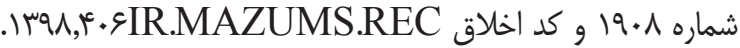
است. از معاونت يزوهشى دانشخاه علوم يزشكى مازندران كه ما را را

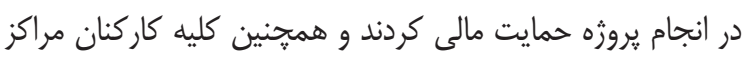

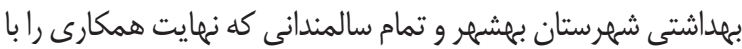

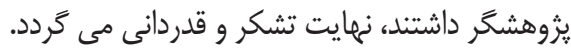

سالمندان با سطح تحصيلات بالاتر، احساس تنهايى كمترى داشتند.

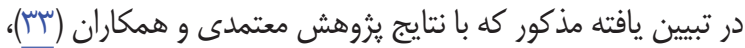

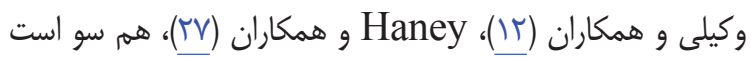

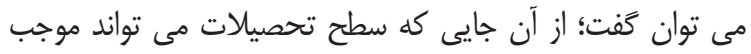

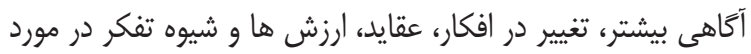

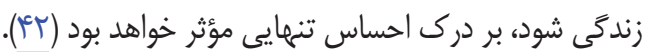
از نتايج ديگر اين يثرهش، ارتباط معنادار بين ميانخًين نمره كل احساس تنهايى و وضعيت درآمد سالمندان شهرى بود. بدين

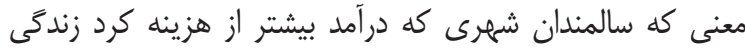
داشتند، احساس تنهايى كمترى مى كردند. در تبيين يافته مذكور

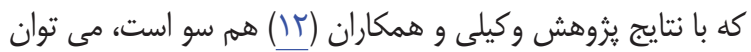

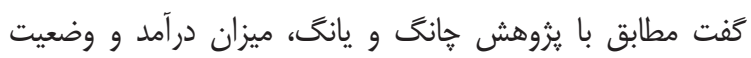

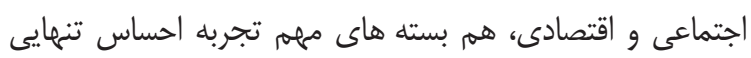
هستند. ميزان تجربه احساس تنهايى با داشتن درآمد بيشتر كه عمدتاً

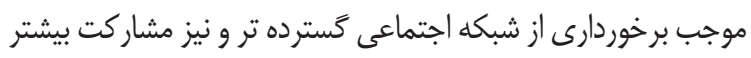

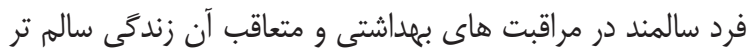

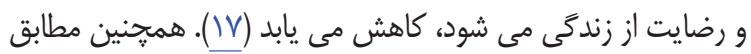

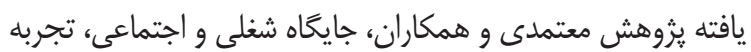

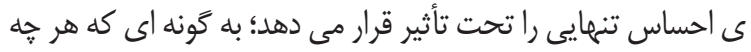
اين جايگاه و ارزش كذارى اجتماعى آن خايين تر باشد، افراد به به ميزان

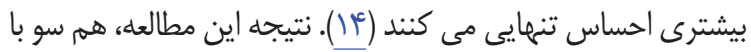
يافته مطالعه ى حاضر است. در مطالعه حاضر مشخص شد، ارتباط معنادارى بين ميانخين

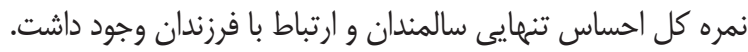

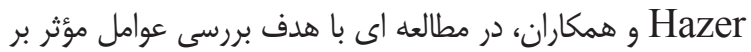

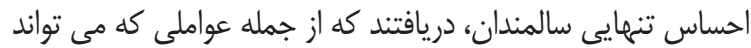
تجربه احساس تنهايى را كاهش دهد شامل: تماس مكرر با فرزندان و بستخان است. سالمندانى كه شبكه اجتماعى ضعيفى دارند، حمايت كافى و رضايت عاطفى را دريافت نمى كنند (ه) (1). Arslantas

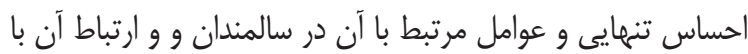

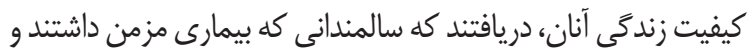
به طور منظهم از داروها استفاده مى كردند احساس تنهايى بيش ترى

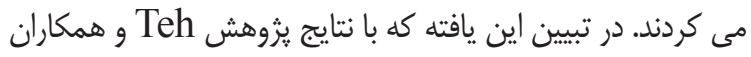

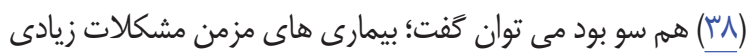

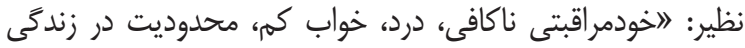

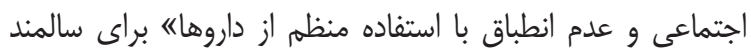

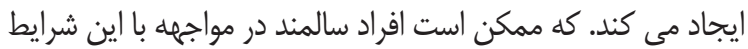
با توجه به محدوديت جسمى و اجتماعى، احساس تنهايى را تجربه كنند. نتايج اين مطالعه با يافته مطالعه حاضر هم سو نبود. 


\section{References}

1. Noroozian M. The Elderly Population in Iran: An ever growing concern in the health system. Iranian Journal of Psychiatry and Behavioral Sciences. 2012; 6 (2):1-6

[Persian].

2. Rashedi V, gharib M, Yazdani A. Social Participation and mental health among older adults in Iran.. Iranian Rehabilitation Journal. 2014; 12 (19): 9-13 [Persian].

3. Statistical center of Iran . Population and Housing census. Available from: http:// amarorgir/ english/ Census. 2016 [persian].

4. Sharifzadeh G, Moudi M,Akhbari S. Investigating health status of older people supported by imam Khomeini. Iranian Journal of ageing. 2010; 3 (7): 52-60 [Persian].

5. Zhou G, Wang Y, Yu X. Direct and Indirect Effects of Family Functioning on Loneliness of Elderly Chinese Individuals. Current Psychology. 2016: 1-7.

6. Khademi MJ, Rashedi V, Sajadi S, Gheshlaghi SM. Anxiety and loneliness in the Iranian older adults. International Journal of Psychology and Behavioral Sciences. 2015; 5 (2): 49-52.

7. Domenech-Abella J, Lara E, Rubio-Valera M, Olaya B, Moneta MV, Rico-Uribe LA, et al. Loneliness and depression in the elderly: the role of social network. Soc Psychiatry Psychiatr Epidemiol. 2017; 52 (4): 381-90.

8. Hawakley L, Cacioppo J. Loneliness Matters. Ann Behav Med. 2010;40(2):218-27.

9. Andrew N, Meeks S. Fulfilled preferences, perceived control, life satisfaction, and loneliness in elderly long-term care residents. Aging Ment Health. 2018; 22 (2): 183-9.

10. Wong NM, Liu HL, Lin C, Huang CM, Wai YY, Lee $\mathrm{SH}$, et al. Loneliness in late-life depression: structural and functional connectivity during affective processing. Psychol Med. 2016; 46 (12): 2485 - 99.

11. Garssen B, Visser A. The association between religion/spirituality and mental health in cancer. Cancer. 2016; 122 (15): 2440-.

12. Vakili M, Mirzaei M, Modarresi M. Loneliness and Its Related Factors among Elderly People in Yazd. Elderly Health Journal. 2017; 3 (1): 10 - 5 [Persian].

13. Heidari M, Ghodusi Borujeni M, Naseh L. Comparison of Self-Efficacy and
Loneliness Between Community-Dwelling \& Institutionalized Older People. Iranian Journal of Ageing. 2016; 11 (1): 142 - 51 [Persian].

14. Moatamedi A, Qaderi Bagajan K, Mazaheri Nejad Fard G, Soltani S. Comparative Study of Feeling Lonely Between Retired and Labor Elderly Men. Quarterly Journal of Social Work. 2017; 6 (2): 43 - 50 [Persian].

15. Hazer O, Boylu AA. The examination of the factors affecting the feeling of loneliness of the elderly. Procedia-Social and Behavioral Sciences. 2010; 9: 2083-9.

16. Zarghami H, Mahmoudian H. Children s OutMigration and Loneliness Feeling in Rural Older Parents. Quarterly Journal Of Health Psychlogy. 2017; 5 (19): 103 - 22 [Persian].

17. Chen Y, Hicks A, While AE. Loneliness and social support of older people in China: a systematic literature review. Health Soc Care Community. 2014; 22 (2): 113-23.

18. Jones DA, Victor CR, Vetter NJ. The problem of loneliness in the elderly in the community: characteristics of those who are lonely and the factors related to loneliness. JR Coll Gen Pract. 1985; 35 (272): 136-9.

19. Hawkley LC, Thisted RA, Masi CM, Cacioppo JT. Loneliness Predicts increased blood pressure: 5 -year cross-lagged analyses in middle-aged and older adults. Psychology and aging. 2010; 25 (1): 132-41.

20. Santini ZI, Fiori KL, Feeney J, Tyrovolas S, Haro JM, Koyangi A. Social relationships,loneliness, and mental health among older men and women in Ireland:A Prospective community-based study. J ournal of affective disorders. 2016; 204: 59-69.

21. Ramic E, Pranjic N, Batic-Mujanovic O, Karic E, Alibasic E. The effect of loneliness on malnutrition in elderly population. Archives of internal medichine. 2011; 65 (2): 92 - 5.

22. Christiansen J, Larsen FB, Lasgard M. Do stress, health behavior,and sleep mediate the association between loneliness and adverse health condition among older people? Social Science\&/Medicine. 2016 (152): 80-6.

23. Hawkley L, Preacher KJ, Cacioppo JT. Loneliness impairs daytime functioning but not sleep duration. health Psycho. 2010; 29 (2):1249. 
24. Wilson C, Moulton B. Loneliness among older adults: A national survey of adults $45+$. Washington, DC: AARP. 2010.

25. Dong $X$, Simon MA. Health and aging in a Chinese population: urban and rural disparities. Geriatrics \& Gerontology International. 2010; 10 (1): 85-93.

26. Havens B, Hall M, Sylvestre G, Jivan T. Social isolation and loneliness: Differences between older rural and urban Manitobans. Canadian Journal on Aging/la revue canadienne du vieillissement. 2004; 23 (2): 129 - 40.

27. Haney MQ, Bahar Z, Beser A, Acil D, Yardimci T, Comes S. Factors Related to Loneliness Among the Elderly Living at Home in Turkey. Turkish Journal of Family Medicine and Primary Care. 2017; 11(2):71-8.

28. Ditommaso E, Brannen C, Best LA. Measurement and validity characteristics of the short version of the social and emotional loneliness scale for adults. Educational and Psychological Measurement. 2004; 64 (1): 99-119.

29. Jowkar B, Salimi A. Psychometric properties of the short form of the social and emotional loneliness scale for adults (SELSA-S). International Journal of Behavioral Sciences. 2011;5 (4): 311-7 [Persian].

30. Validation of Geriatric Depression Scale (GDS15) in Iran. Research-in-Medicine. 2006; 30 (4):361-9 [Persian].

31. Foroughan M, Wahlund LO, Jafari Z, Rahgozar M, Farahani IG, Rashedi V. Validity and reliability of A bbreviated $\mathrm{M}$ ental $\mathrm{T}$ est $\mathrm{S}$ core (AMTS) among older I ranian. Psychogeriatrics. 2017; 17(6): 460 - 5.

32. Habibi Sola A, Nikpoor S, Rezaei M, Haghani H. Health Promotion Behaviours and Level of Activities of Daily Living and Instrumental Activities of Daily Living Among Elderly People in West Region of Tehran: A Cross-Sectional Survey. Iranian Journal of Ageing. 2007; 2 (3): 331-9 [Persian].

33. Motamedi N, Shafiei-Darabi SM, Amini Z. Social and Emotional Loneliness among the Elderly; and its Association with Social Factors Affecting Health in Isfahan City. Journal of Isfahan Medical School. 2018; 36 (486): 750 - 6 [Persian].

34. Narusawa A, Sakata Y, Takata Y. Loneliness and its associated Factors in Community-living Elderly People who Use Day Care Services. Japanese Journal of Health and Human Ecology. 2017; 83 (5):139-48.

35. Hajihashemi Z, Vameghi R, Montazeri A, Sohrabi MR, Akbari-Kamrani A. Comparing quality of life among rural and urban elderly outpatients. Iranian Institute for Health Sciences Research. 2013 (12): 255-62 [Persian].

36. Cacioppo JT, Hawkley LC, Ernst JM, Burleson M, Berntson GG, Nouriani B, et al. Loneliness within a nomological net: An evolutionary perspective. Journal of research in personality. 2006; 40 (6):1054-85.

37. Hemati G, Dehshiry G, Shijaei S, Hakimi E. Comparative loneliness and general health infielders with family and residential care in North on Tehran. J elderly in Iran. 2009; 8 (3): 557-64 [persian].

38. Teh JKL, Tey NP, Ng ST. Family support and loneliness among older persons in multiethnic Malaysia. The scientific world journal. 2014; 2014.

39. Phaswana-Mafuya N, Peltzer K. Prevalence of Loneliness and Associated Factors among Older Adults in South Africa. Global Journal of Health Science. 2017; 9 (12): 1.

40. Liu LJ, Guo Q. Loneliness and health-related quality of life for the empty nest elderly in the rural area of a mountainous county in China. Qual Life Res. 2007; 16 (8): 1275 - 80.

41. Alipour F, Sajadi H, Forouzan A, Biglarian A, Jalilian A. Quality of life in elderly region 2 Tehran. Iranian journal of ageing. 2008; 3 (9): 10 [persian].

42. Sheibbani F, Pakdaman S, Dadkhah A, Tavakoli $\mathrm{MH}$. [The effect of music therapy on depression and loneliness in old people Journal of agieng 2010; 5 (2): 54 - 60 [Persian].

43. Arslantas H, Adana F, Abacigil Ergin F, Kayar D, Acar G. Loneliness in Elderly People, Associated Factors and Its Correlation with Quality of Life: A Field Study from Western Turkey. Iran J Public Health. 2015; 44 (1): 43 - 50. 